\title{
Diagnostic Accuracy of a Smartphone-Operated Single-Lead ECG for Detection of Rhythm and Conduction Abnormalities in Primary Care
}

\author{
Divya Manda, MD, Grant Family Medicine; Michael E Jobansen, MD, MS, Associate Editor \\ Ann Fam Med 2019;17(5):iii. https://doi.org/10.1370/afm.2458.
}

The Annals of Family Medicine encourages readers to develop a diverse learning community to think critically about important issues affecting primary care, conduct journal clubs, and act on those discussions. ${ }^{1}$

\section{HOW IT WORKS}

In each issue, the Annals selects an article and provides discussion tips and questions. Post a summary of your conversation in our online discussion. (Open the article and click on "TRACK Discussion/ Submit a comment.") Discussion questions and information are online at: http://www.AnnFamMed.org/site/AJC/.

\section{CURRENT SELECTION}

\section{Article for Discussion}

Himmelreich JC, Karregat EP, Lucassen WA, et al. Diagnostic accuracy of a smartphone-operated, single-lead ECG for detection of rhythm and conduction abnormalities in primary care. Ann Fam Med. 2019;17(5):403-411.

\section{Discussion Tips}

Many patients present to primary care physicians with symptoms that are suspicious for cardiac arrhythmias, but 12-lead ECGs to evaluate the symptoms are not always available or are cumbersome. This article describes a blinded case series to evaluate the utility of a smartphone-enabled 1-lead ECG.

\section{Discussion Questions}

- What does this study investigate and why does this matter?

- How is this study different from previous studies about smartphone-enabled ECGs? What does this study add to the field?

- How strong is the study design to answer the researchers' questions?

- Define sensitivity, specificity, likelihood ratios, positive/ negative predictive value. How are these calculated?

-What are some criticisms about the use of these values? $?^{2,3}$
- What were the primary and secondary findings of the study? How accurate was 1-lead ECG for detecting atrial fibrillation/atrial flutter vs other arrhythmias vs ectopic beats? Is there value in combining these end points?

- Importantly, what does this study not investigate?

- To what degree can the findings be accounted for by:

- How patients were selected, excluded, or lost

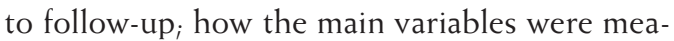
sured?; confounding variables; and how the findings were interpreted?

- How applicable are the study results to your patient population? How applicable are the study results in a typical primary care office? What is the transportability of the findings?

- How might spectrum bias be relevant to this study?

- How might the study change your practice? Would you be more likely to use a smartphone-enabled 1-lead ECG in your office or at home visits?

-What are the limitations of the study and how may this limit the applicability of the results?

- How does this study relate to and differ from the discussion around using smartphone ECG as a screening tool? ${ }^{4}$

-What are next steps in applying the findings to clinical practice and in primary care?

- What research questions remain regarding the use of smartphone-enabled 1-lead ECGs in primary care?

\section{References}

1. Stange KC, Miller WL, McLellan LA, et al. Annals Journal Club: It's time to get RADICAL. Ann Fam Med. 2006;4(3):196-197. http:// annfammed.org/cgi/content/full/4/3/196

2. Janssens AC, Deng Y, Borsboom GJ, Eijkemans MJ, Habbema JD, Steyerberg EW. A new logistic regression approach for the evaluation of diagnostic test results. Med Decis Making. 2005;25(2):168-177.

3. McNutt R, Hadler NM. Rethinking our thinking about diagnostic tests: there is nothing positive or negative about a test result. https://thehealthcareblog.com/blog/2015/12/01/rethinking-aboutdiagnostic-tests-there-is-nothing-positive-or-negative-about-a-testresult/. Accessed Aug 9, 2019.

4. Mandrola J, Foy A. Downsides of detecting atrial fibrillation in asymptomatic patients. Am Fam Physician. 2019;99(6):354-355. 